\title{
Medical student research at Texas Tech University Health Sciences Center: Increasing research participation with a summer research program
}

\author{
Steven L. Berk MD
}

Medical schools have generally advocated that medical students have research experiences during their undergraduate medical school years. ${ }^{1,2}$ Most provide a wide range of elective experiences and a few require a research project and thesis. Chang and Ramnanan ${ }^{3}$ reviewed the literature and identified 20 papers on medical student research experiences as measured by self- reported surveys. Students usually found such experiences to stimulate research interest and encourage scholarship. The $\mathrm{NIH}^{4}$ and Howard Hughes Medical Institute ${ }^{5}$ have shown that intense research experiences in medical students can produce life-long commitments to research as physician-scientists and physicians who choose a career in academic medicine.

Not all students will choose research or academic careers; and in the current health care environment with an increasing shortage of practicing physicians, particularly in primary care, it is not the goal of medical schools like Texas Tech Health University Health Sciences Center School of Medicine to make all students physician-scientists. But there are real benefits to providing as many students as possible with a research experience.

Medical students are intensely exposed to new ideas, language, concepts, hypotheses, and dogma. Many become energized to think critically and incubate their own new ideas. Few people are as challenged as first year medical students to think critically as they sort out an overwhelming amount of information. Students can become the incubators of novel

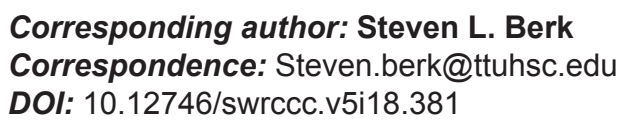

ideas, even if their introduction to research is becoming a member of a team that is pursuing someone else's longstanding idea. As I tell first year medical students interested in a research project, someone had the idea to study the skin of frogs in bacterial contaminated swamps for its antibacterial properties and found a new class of antibiotics. That could have been your idea. Someone made a straw with a bacterial resin and charcoal filter to test its ability to make drinking water palatable in countries or campgrounds where water was too contaminated to drink. That too could have been your idea. Someone concluded that patients with congestive heart failure could be weighed every day by a visiting nurse and large amounts of such data could be computerized and followed to prevent heart failure readmissions. The next great idea or hypothesis could well come from a first year medical student.

Whether doing a basic science or clinical research project, the fundamentals of research and basic techniques provide long standing lessons on how knowledge is obtained and recorded. Pouring over charts in a retrospective study can reveal amazing outcomes or tragic mistakes that will likely be remembered better than any lecture. While studies depending on physicians to complete surveys may be frustrating, compiling such data to understand why physicians don't follow certain guidelines, don't wash their hands, or still use antibiotics for upper respiratory infections will capture the interest of the student and potentially provide useful information to improve patient care.

Last, if program directors have decided that research is an important consideration in the competitive residency selection, medical schools would be remiss in not providing all possible research opportunities. While research experience is not 
high on the list in choosing an applicant for residency program directors as a whole, listed thirteenth in one 2009 study, ${ }^{6}$ it does appear to be a more important factor in competitive programs such as dermatology. ${ }^{7}$

The study in this journal by Dufour, Gregorcyk, and Berk ${ }^{8}$ suggests that a summer research program after the first year of medical school can dramatically increase interest in research among students. This interest can be measured by the percentage of students who find a research mentor, present an abstract and publish a paper.

Keywords: medical students, research, curriculum

Affiliation: Steven Berk is the Dean of the School of Medicine at Texas Tech University Health Sciences Center in Lubbock, TX

Submitted: 4/4/2017

Conflicts of interest: none

\section{REFERENCES}

1. Izutsu S. Importance of research in medical education. Medical School Hotline, February 2012; 71(2): 53-56. https://www. ncbi.nlm.nih.gov/pmc/articles/PMC3313775
2. Zier K, Friedman E, Smith L. Supportive programs increase medical students' research interest and productivity. J Investig Med May 2006; 54(4): 201-207. https://www.ncbi.nlm.nih.gov/ pubmed/17152859

3. Chang Y, Ramnanan CJ. A review of literature on medical students and scholarly research: experiences, attitudes, and outcomes. Acad Med, August 2015; 90(8): 1162-1173. https:// www.ncbi.nlm.nih.go/pubmed/25853690

4. Soloman SS, Tom SC, Pichert J, Wasserman D, Powers AC. Impact of medical student research in the development of physician scientists. J Investig Med May 2003; 51(3): 149-156. https://www.ncbi.nlm.hih.gov/pubed/12769197

5. Fang D, Meyer RE. Effect of two Howard Hughes Medical Institute research training programs for medical students on the likelihood of pursuing research careers. Acad Med December 2003; 78(12): 127-1280. https://www.ncbi.nlm.nih.gov/pubmed/14660432

6. Green M, Jones P, Thomas JX Jr., Selection Criteria for Residency: Results of a National Program Directors Survey. Academic Medicine March 2009; 84(3):362-367. https://www. ncbi.nlm.nih.gov/pubmed/19240447

7. Stratman EJ, Ness RM. Factors associated with successful matching to dermatology residency programs by reapplicants and other applicants who previously graduated from medical school. Arch Dermatology February 2011; 147(2): 196-200. https://www.ncbi.nlm.nih.gov/pubmed/20956631

8. Dufour J, Gregorcyk E, Berk SL. Medical student research at Texas Tech University Health Sciences Center: increasing research participation with a summer research program. The Southwest Respiratory and Critical Care Chronicles 2017; 5 (18): 